\title{
ANUALIDADES A INTERES SIMPLE
}

\section{ERRORES DE LA PRACTICA EN USO}

Las anualidades son un caso particular de las rentas, por las cliales se amortiza una deuda cualquiera. Entre particulares, y cuando la cuantía es relativamente pequeña, se suelen estipular a corto piazo anualidad constante e interés simple.

La obtención de fórmulas matemáticas que resuelvan el problema suele hacerse con ligereza en los libros de cálculo mercantil que tratan de este asunto, cometiéndose errores de algina consideración, base de litigios enire las partes contratantes.

Queremos poner de manifiesto estos errores, para lo cual vamos a deducir fórmulas siguiendo dos procedimientos: primero, valores actuales; segundo, valores finales.

Primer procedimiento.-El valor actual de la deuda es igual a la stma de los valores actuales de las anualidades que la amortizan. $O$ bien: la deuda queda cancelada paganfo a'fin de cada año la parte de capital que corresponde y sus intereses simples en los años transcurridos.

Llamemos $c$ al capital prestado o importe de la deuda; $A$ la anuaijdad que la amortiza; $r$ el tanto de interés anual y $n$ el número de años. Tendremos:

$$
c=\frac{A}{1+r}+\frac{A}{1+2 r}+\cdots \cdots \cdots \cdots \cdots \cdots \cdots \cdots \cdots \cdots \cdots \cdots+\frac{A}{1+n r}
$$

y sacando factor común a $A$ :

$$
c=A\left[\frac{1}{1+r}+\frac{1}{1+2 r}+\cdots \cdots \cdots \cdots \cdots \cdots \cdots \cdots \cdots \cdots+\frac{1}{1+n r}\right]
$$

la expresión entre corchetes, cuando $n$ es limitado, carece de fórmula general sumatoria y, por tarto, sólo se puede hallar su valor en cada caso particular (*).

Segurido procedimien/o.-El valor final de la deuda es igual a la suma de los valores finales de las anualidades que la amortizan. $O$ bien: si el deuitor devenga interés for la cantida'd que recibe el acreedor lo devenga también por las cantidades que se le devuelven.

Hac:endo uso de los mismos e.emen:os de cálculo tentremos:

$$
r(1+n r)=\mathrm{A}(1+(n-1) r)+\mathrm{A}(1+(n-2) r)+\cdots \cdots \cdots \cdots \cdots \cdots \cdots \cdots
$$

84 (*) Cuando $n$ es ilimitado la expresión constituye una serie alvergente (serie armonica). 
y sacando factor común a $A$ :

$$
c(1+n r)=\mathrm{A}[(1+(n-1) r)+(1+(n-2) r)+\ldots \ldots \ldots+\cdots
$$

Haciendo operaciones indicadas, stmando ordenadamemte, sacando factor comba a $r$ y sumando la progresión aritmética resultante, hallaremos la siguiente expre: sión como valor de la anualidar:

$$
A=\frac{2 c(1+n r)}{n(2+r(n-1))}
$$

Esta fórmula es la que figura en todos los libros de cálculo mercantil que tratag de esta cuestión.

Vamos a comparar los dos procedimientos, para lo cual pondremos las formulas de la siguiente manera, con subindices en la anualidad, según sea el primero o gundo procedimiento:

$$
\begin{aligned}
& \frac{c}{\mathrm{~A}_{1}}=\frac{1}{1+r}+\frac{1}{1+2 r}+\cdots \cdots \cdots \cdots \cdots \cdots \cdots \cdots+\frac{1}{1+\frac{n}{n} r} \\
& \frac{c}{A_{2}}=\frac{1+(n-1) r}{1+n r}+\frac{1+(n-2) r}{1+n r}+\stackrel{n}{n} \ldots+\frac{1}{1+n r}
\end{aligned}
$$

Teniendo los segundos miembros' $n$ términos cada uno es fácil demostrar que un término cualquiera del primer miembro es menor que su correlativo del segundo miembro, excepto los últimos, que son idénticos. Fijándonos en los que ocupan el lugar $h$ tendremos:

$$
\frac{1}{1+h r}<\frac{1+(n-h) r}{1+n r} ; \quad h<n
$$

Reduciendo a un común denominador, efectuando operaciones indicadas y suprimiendo términos opuestos se tentrá:

$$
\frac{1}{1+h r}<\frac{1}{1+h r}+\frac{r^{2} h(n-h)}{(1+h r)(1+n r)}
$$

Y como la anualidad aparece como divisor en las fórmulas expresadas, resulta:

$$
A_{1}>A_{2}
$$

Un ejemplo sencillo aclarará esta cuestión: Sea un préstamo de 90.000 pesetas, el 5 por 100 anual, durante cuatro años. ¿Qué anualidad lo amortizará?

Primer procedimiento:

$$
90^{\prime} .000=A_{1}\left[\frac{1}{1^{\prime} 05}+\frac{1}{1^{\prime} 10}+\frac{1}{1^{\prime} 15}+\frac{1}{1^{\prime} 20}\right] ; A_{1}=25.249^{\prime} 90 \text { pesetas. }
$$




\section{Comprobación:}

\begin{tabular}{|c|c|c|c|c|c|}
\hline Años & $\begin{array}{c}\text { Capital } \\
\text { amortizado }\end{array}$ & $\begin{array}{l}\text { Intereses } \\
\text { pagados }\end{array}$ & $\begin{array}{c}\text { Total } \\
\text { anualidad }\end{array}$ & & Observaciones \\
\hline $\begin{array}{l}\mathbf{1} \\
2 \\
3 \\
4\end{array}$ & $\begin{array}{l}24.047,60 \\
22.954,45 \\
21.956,40 \\
21.041,55\end{array}$ & $\begin{array}{l}1.202,30 \\
2.295,45 \\
3.293,50 \\
4.208,35\end{array}$ & $\begin{array}{l}25.249,90 \\
25.249,90 \\
25.249,90 \\
25.249,90\end{array}$ & \multirow{2}{*}{\multicolumn{2}{|c|}{ 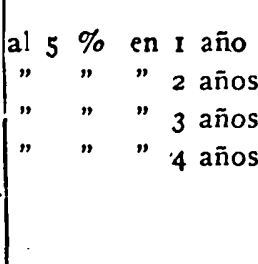 }} \\
\hline & $90.000,00$ & $10.999,60$ & $100.999,60$ & & \\
\hline
\end{tabular}

Segundo prócedimiento:

$$
A_{2}=\frac{2 \times 90.000 \times 1^{\prime} 20}{4 \times 2^{\prime} 15} ; A_{2}=25.116^{\prime}: 0 \text { pesetas. }
$$

Comprobación :

Valor final del préstamo

$108.000,00$

1.: Anualidad a interés en 3 años

$28.883,70$

2." Anualidad a interés en 2 años

$27.627,90$

3." Anualidad a interés en $I$ año ...... 26.372,10

4. Anualidad sin interés

$25.116,30$

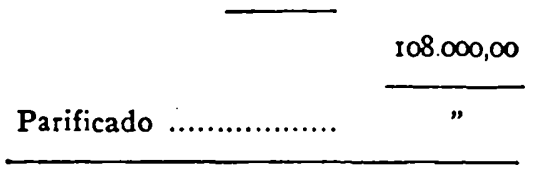

Se aprecia una diferencia de consideración entre ambos procedimientos, pues, a - pesar de la poca cuantía de la ideuda y los pocos años de amortización, la diferencia total es superior a 500 pesetas.

¿Cliál es el procedimiento verdadero? Para el acreedor o prestamistá sería el primero. Para el deujor o prestatario sería el segundo, y como consecuencia de esta disparidad de criterios surgiría el pleito. El juez llamaría a un perito para informar sobre el asunto y a la vista del informe resolvería.

¿Por qué procedimiento se pronunciaría el perito? Acaso por el segundo, basándose en que la fórmula del mismo es la preconizada por todos los tratadisias de calculo mercantil.

Sin emoargo, un detenido análisis de la cuestión nos pondría de manifiesto e] error de tal fórmula y la bonjad del primer procedimiento. Recordemos la característica de las anialidades a interés simple: sólo producen interés los capitales pres-

86 tades. Representemos por $K$ el segundo miembro de la fórmula (I) y sustituyamos 
cada sumando de la fórmula (2) por su valor en función de las diferencias que indica la desigcialdad (3); se tendrá:

$$
\begin{gathered}
c=A_{1} \cdot \mathrm{K} \\
c=A_{2} \cdot \mathrm{K}+\sum_{h=1}^{n} \frac{\mathrm{A}_{2} r \cdot h}{1+h r} \cdot \frac{r(n-h)}{1+n r}
\end{gathered}
$$

Vemos que mientras en el primer procedimiento el valor actuxi de la deuda es correctamente igual a la suma de los valores actuales de las anualidades, en el segundo procedimiento el vaior actual de la deuda es igual a la suma cie los valores actlales de las anualidades, más la suma de los valores actuales del interés de tales anualidades por el tiempo que falta para terminar e! plazo convenido, lo cual es absurdo, ya que el interés en estas anualidades no es rentable.

Teniencio esto en cuenta, la anualidal $A$ del primer procedimienio satisface la condición del segutrido procedimiento, estableciéndo.a correctamente. Si el deudor devenga interés por la cantidad que recibe el acreedor los devengará también por las cantidades que se le devuelven en concepto de capital. forma :

En efecto, este principio se comprobará en el ejemplo propuesto de la siguiente

$$
\text { Intereses totales del préstamo } \ldots \quad 18.000,00
$$

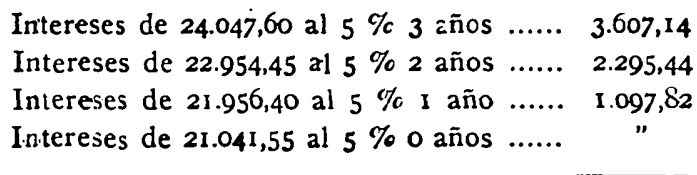

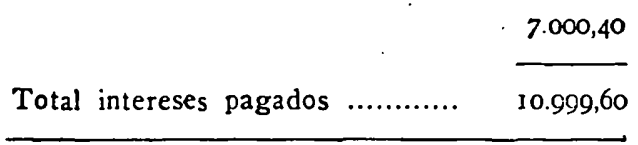

En resumen: la única fórmula verdadera de las anuaiidades constantes y a interés simple es la siguiente:

$$
A=\frac{c}{\sum_{h=1}^{n} \frac{1}{1+h r}}
$$

Por tanto, las fórmulas insertas en los textos de cálculos mercantiles deben rechazarse por erróneas.

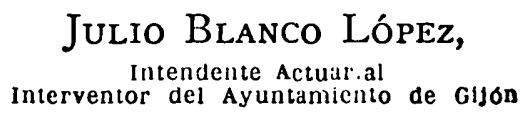

